\title{
Aerococcus urinae causing Infective endocarditis in a patient with Down's syndrome with ventricular septal defect
}

Valentine LIETAERT ${ }^{1}$, Georgeta CORNEA ${ }^{1}$, Perrine KUCZERA-NAESSENS ${ }^{1}$, Alexandre MONTMUREAU ${ }^{1}$, Gisèle DEWULF ${ }^{2}$, and ARNAUD DZEING ELLA ${ }^{1}$

${ }^{1}$ Centre Hospitalier de Denain

${ }^{2}$ Centre Hospitalier de Valenciennes

January 7, 2021

\begin{abstract}
Aerococcus urinae is rare in infective endocarditis. The best known risk factors are urogenital comorbidities. We report the case of a 46-year-old male with Down's syndrom with infective endocarditis. The patient underwent successful treatment with amoxicillin and heart surgery with valve replacement.He had an unknown ventricular septal defect
\end{abstract}

\section{Hosted file}

A urinae for publication _CRC final.pdf available at https://authorea.com/users/387970/ articles/502845-aerococcus-urinae-causing-infective-endocarditis-in-a-patient-with-downs-syndrome-with-ventricular-septal-defect 


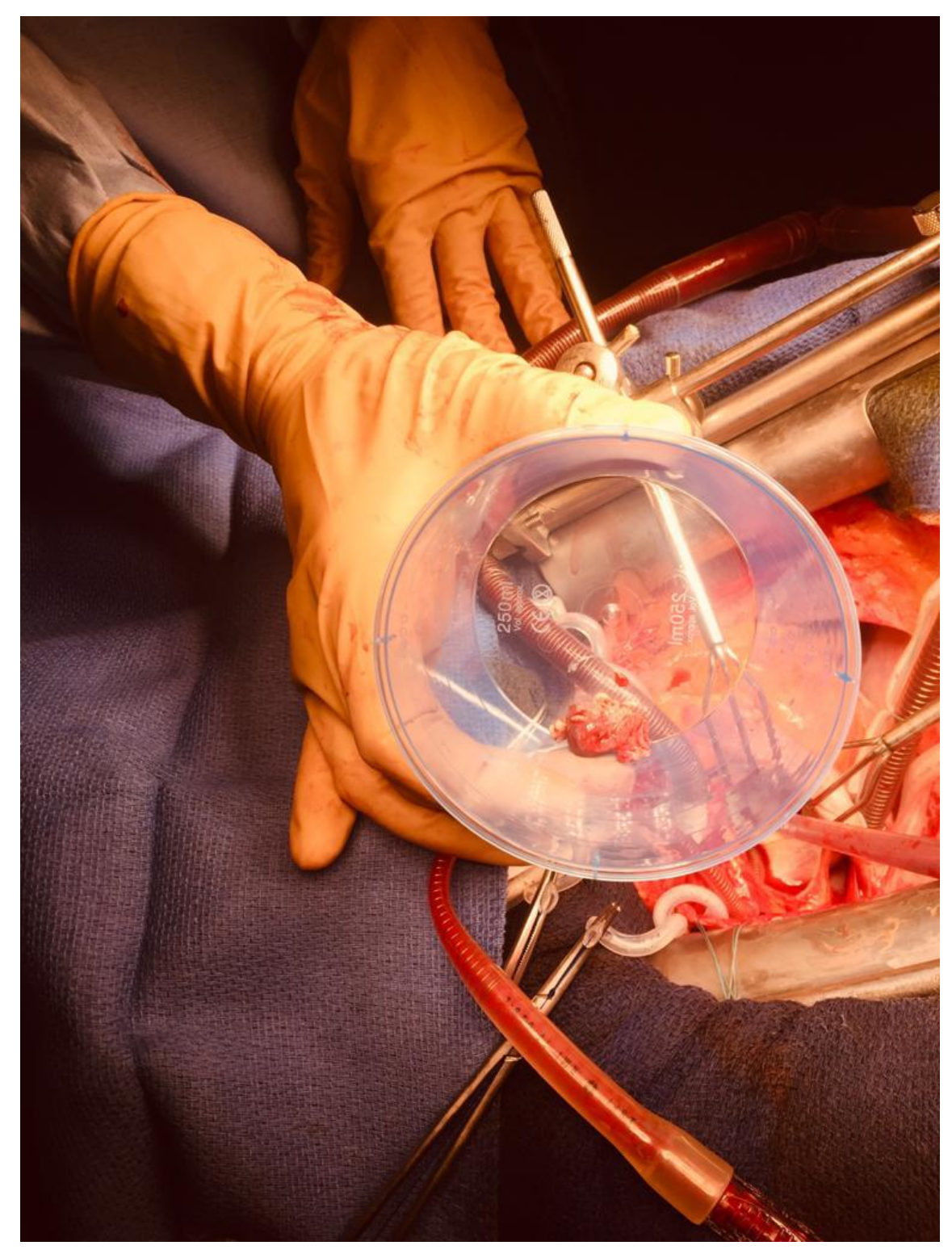

